\title{
Effects of nitrogen source and growth phase on proximate biochemical composition, lipid classes and fatty acid profile of the marine microalga Isochrysis galbana
}

J.P Fidalgo ${ }^{a}$ A Cida ${ }^{a}$ E Torres ${ }^{a}$, A Sukenik $^{b}$, C Herrero $^{a 1}$,

Aquaculture Volume 166, Issues 1-2, 1 July 1998, Pages 105-116

Accepted 28 April 1998, Available online 16 September 1998

DOI: $10.1016 / S 0044-8486(98) 00278-6$

\begin{abstract}
The marine microalga Isochrysis galbanawas cultured in nitrate, nitrite or urea media to examine changes in the gross biochemical composition, with special emphasis on the growth phase associated changes in the compositions of the lipid classes and fatty acids. The gross biochemical composition was affected more by the growth phase than by the nitrogen source. Protein was higher during exponential growth (about 37-45\% AFDW) but the pattern changed as the cultures aged, and lipids were the main algal constituents on all nitrogen sources in the late stationary phase. In all cultures, the relative abundance of neutral lipid increased in the late stationary phase concomitant with a proportional reduction in phospholipids, whereas galactolipids only slightly changed during the growth of the cultures. Total fatty acid content was affected by nitrogen source and growth phase. Maximal PUFA values were obtained at the early stationary phase and decreased throughout the stationary phase. The highest fatty acid contents in the early stationary phase were produced in urea cultures; these cultures also had higher PUFA content, with EPA and DHA contents of $27.66 \%$ and $14.13 \%$ of total fatty acids, respectively.
\end{abstract}

Keywords

Isochrysis galbana; Nitrogen sources; Lipids; Fatty acids

\section{Introduction}

Microalgae play an important role in mariculture as food for larval and juvenile molluscs, crustacean and fish species. The nutritional value of microalgae is related to their biochemical composition, especially the lipid and fatty acid compositions (Sukenik and Wahnon, 1991;

\footnotetext{
1 a Laboratorio de Microbiología, Facultad de Ciencias, Universidade da Coruña, Campus da Zapateira s/n, 15071 A Coruña, Spain b National Institute of Oceanography Israel Oceanographic and Limnological Research Tel Shikmona, P.O.B. 8030, Haifa 31080, Israel
} 
Dunstan et al., 1992 and Dunstan et al., 1993;Sukenik et al., 1993). The quality and quantity of microalgal lipid are important to the nutrition of marine animals (Enright et al., 1986; Gallager et al., 1986; Koven et al., 1989; Sargent et al., 1989). Dietary lipids are sources of both metabolic energy and specific metabolites that are essential for animal growth. The most important aspect of lipid in animal nutrition is the content and proportions of certain fatty acids. In particular, it has been shown that some polyunsaturated fatty acids (PUFAs) synthesized by algae, are essential for the growth and development of marine fish larvae (Koven et al., 1989), shrimp and molluscs (De Pauw and Persoone, 1988). The presence of long-chain $n-3$ highly unsaturated fatty acids is important in selecting unicellular marine algae for aquacultural purposes, in particular, eicosapentaenoic acid (EPA), 20:5n-3, and docosahexaenoic acid (DHA), 22:6n-3.

The golden-brown flagellate /sochrysis galbana has been utilized successfully as a food source for a variety of bivalve molluscs ( Enright et al., 1986) and is one of the most commonly used marine unicellular algae in many mariculture systems (Sukenik and Wahnon, 1991). I. galbana is rich in polyunsaturated fatty acids (PUFAs), and grows well in mass cultures, either indoors or outdoors ( Kaplan et al., 1986).

The manipulation of the algal growth environment can alter the growth characteristics and chemical composition of cells cultured under the conditions applied (Brown et al., 1989). Among the different components of the culture medium, the source and concentration of nitrogen can provoke important changes in the growth and biochemical composition of microalgal species (Kaplan et al., 1986; Levasseur et al., 1993;Fidalgo et al., 1995). The chemical composition of microalgal cells is also known to vary during their growth phase, particularly with respect to their lipid component (Sukenik and Carmeli, 1990; Hodgson et al., 1991).

In order to optimize the lipid and fatty acid production, I. galbanawas cultured with different nitrogen sources. The gross biochemical composition (protein, carbohydrate and lipid) was examined, with special emphasis on the growth phase associated changes in the composition of the lipid classes and fatty acids.

\section{Materials and methods}

\subsection{Organism}

1. galbana Parke clon ISO (Haptophyceae) was obtained from the Culture Center of Algae and Protozoa, Cambridge, England.

\subsection{Growth conditions}

Cultures were carried out in sterilized and enriched seawater (salinity $36 \mathrm{~g} \mathrm{l}^{-1}$ ) (Fidalgo et al., 1995). Nitrogen sources used were: nitrate, as $\mathrm{NaNO}_{3}$, nitrite, as $\mathrm{NaNO}_{2}$, and urea $\left(\left(\mathrm{NH}_{2}\right)_{2} \mathrm{CO}\right)$, all at a concentration of $4 \mathrm{mg}$ atom $\mathrm{N} \mathrm{I}^{-1}$.

Cultures were grown in a controlled environmental incubator at $18 \pm 1^{\circ} \mathrm{C}$ and illuminated with Mazda Fluor C7 TF40 fluorescent lamps, at an irradiance level of $115 \mu \mathrm{mol} \mathrm{m} \mathrm{m}^{-2} \mathrm{~s}^{-1}$. A 12:12 
light-dark cycle was maintained in order to obtain synchronous cultures. Cultures were continuously bubbled with $0.22 \mu \mathrm{m}$ filtered air at a rate of $10 \mathrm{I} \mathrm{min}^{-1}$. Axenic stock cultures were grown in nitrate media. Inocula were taken from the same stock culture at late exponential growth phase, and initial densities were adjusted to $2.5 \times 10^{6}$ cells $\mathrm{ml}^{-1}$. Algal cells were not preadapted to the new $\mathrm{N}$ source. Experiments were carried out in triplicate.

\subsection{Growth measurement}

Cell numbers were measured daily using an electronic particle counter (Coulter Electronics), pH was recorded, and instantaneous growth rates $(\mu)$ were calculated.

\subsection{Analytical methods}

Cells were harvested at three different points in the growth curve: during the exponential growth phase, in an early stationary phase, and during the late stationary phase (Fernandez-Reiriz et al., 1989). Samples were always collected at the same moment in the photoperiod. Dry weight was determined according to Vonshak (1986)and ash content as A.O.A.C. (1980). C/H/N was determined with an elemental analyser (Carlo-Herba). Protein content was derived from nitrogen content using the factor proposed by Gnaiger and Bitterlich (1984). Carbohydrates were measured by the phenol sulphuric acid method (Kochert, 1978). Pigments were extracted in $90 \%$ acetone and concentrations were calculated as previously described (Sukenik and Wahnon, 1991).

\subsection{Extraction and quantification of lipids}

Total lipids were extracted with methanol:chloroform:water $(2: 1: 0.8 \mathrm{v} / \mathrm{v} / \mathrm{v})$. Total lipids were quantified by the charring method (Marsh and Weinstein, 1966). Total lipid extracts were fractionated to the major lipid groups on heat activated silicic acid columns (Sep-Pak silica cartridges, Waters) as previously described (Sukenik et al., 1989).

\subsection{Preparation and determination of fatty acids}

Fatty acid methyl esters were analyzed from freeze-dried biomass following the procedure described by Miller (1984)using a Perkin-Elmer 8310 gas-liquid chromatograph with FID detector equipped with a 30-m fused silica capillary column SP-2330 (Supelco). Identification of fatty acid methyl esters was accomplished by comparing the retention times of experimental samples to those of known standards. Identification was verified by GC-MS using a HewlettPackard gas-liquid chromatograph connected to an HP5972 mass selective detector using both SP-2330 and Omegawax 250 (Supelco) analytical columns. Margaric acid (C17:0) was used as internal standard.

\subsection{Statistical analysis}

Data were analyzed using ANOVA and the Duncan multiple range test $(\alpha=0.05)$. 


\section{Results}

\subsection{Algal growth}

1. galbana grew, in the three different nitrogen sources at a similar rate, with no significant differences among them ( $P>0.05)$ ( Fig. 1). Maxima instantaneous growth rates $(\mu)$ were 0.781 for nitrate, 0.76 for nitrite and 0.73 for urea media. There were no significant differences among the cellular densities reached at the stationary phase $(P>0.1)$.

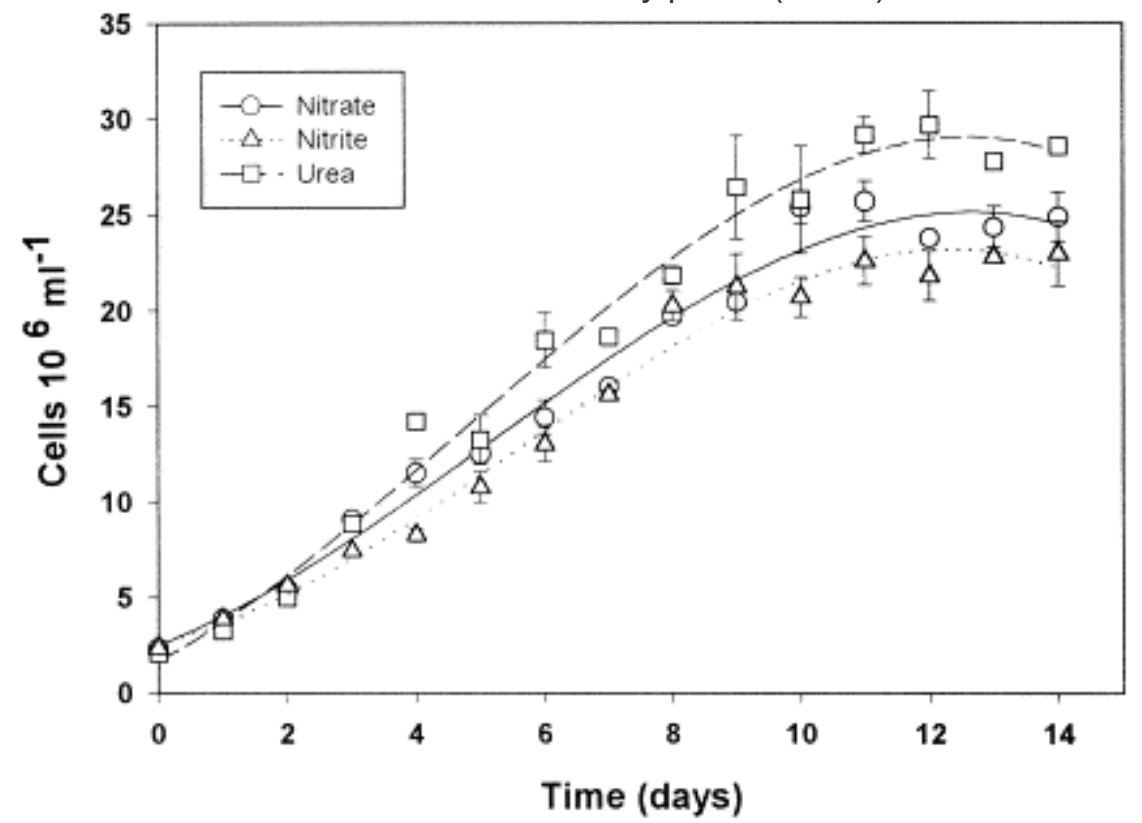

Fig. 1.

Growth curves of I. galbana cultured with different nitrogen sources.

Dry weights, ash percentages and organic matter (AFDW, ash free dry weight) of cells were affected by the growth phase and by the $\mathrm{N}$-source (Table 1). In all the $\mathrm{N}$-sources assayed, cellular dry weight tended to increase when the culture aged, from values of about 41-53 pg cell ${ }^{-1}$ at the logarithmic phase to values of about $65-83$ pg cell-1 $^{-1}$ at the late stationary phase. Similar results were obtained for the organic cell weights, increasing from $30-40$ pg cell-1 to $55-68 \mathrm{pg}$ cell-1. $^{-1}$ There were no significant differences in cell dry weights and organic dry weights between the logarithmic and early stationary phases in nitrate and urea cultures, but significant differences occurred between early and late stationary phases in all cultures. In late stationary phase, cells grown in nitrate and urea had significantly higher dry weights and organic weights than cells grown in nitrite (Table 1). Consequently, dry weight yields and organic matter (AFDW) yields at late stationary phase were significantly higher in nitrate and urea cultures than in nitrite cultures. Ash content was significantly higher in the logarithmic phase than in the stationary phase in all cultures (Table 1).

Table 1.

Dry weight (DW), ash content, and ash-free dry weight (AFDW) of $/$. galbana grown in different $\mathrm{N}$ sources

Parameter Phase Nitrate Nitrite Urea 


\begin{tabular}{|c|c|c|c|c|}
\hline Parameter & Phase & Nitrate & Nitrite & Urea \\
\hline \multirow[t]{3}{*}{ DW $\left(p g\right.$ cell $\left.^{-1}\right)$} & $\mathrm{L}$ & $47.50 \pm 1.65(\mathrm{a}, \mathrm{b})$ & $53.38 \pm 0.95(b)$ & $41.05 \pm 0.16$ (a) \\
\hline & ES & $49.00 \pm 1.47(a, b)$ & $44.68 \pm 0.45$ (a) & $42.68 \pm 1.29$ (a) \\
\hline & LS & $76.46 \pm 10.78(\mathrm{~d})$ & $65.40 \pm 6.48(\mathrm{c})$ & $83.44 \pm 2.19(\mathrm{~d})$ \\
\hline \multirow[t]{3}{*}{ Ash (\%DW) } & $\mathrm{L}$ & $27.82 \pm 1.29(\mathrm{~b})$ & $24.82 \pm 1.21(\mathrm{~b})$ & $25.83 \pm 0.10(b)$ \\
\hline & ES & $15.73 \pm 0.20(a)$ & $16.25 \pm 0.75(\mathrm{a})$ & $17.25 \pm 0.24$ (a) \\
\hline & LS & $16.21 \pm 0.65(\mathrm{a})$ & $16.24 \pm 0.72(\mathrm{a})$ & $17.81 \pm 0.50$ (a) \\
\hline \multirow[t]{3}{*}{ AFDW (pg cell ${ }^{-1}$ ) } & $\mathrm{L}$ & $34.20 \pm 1.28(a, b)$ & $40.03 \pm 2.51(b)$ & $30.38 \pm 2.76$ (a) \\
\hline & ES & $41.16 \pm 1.25(\mathrm{a}, \mathrm{b})$ & $37.53 \pm 0.47(\mathrm{a})$ & $35.42 \pm 1.12$ (a) \\
\hline & LS & $64.23 \pm 9.07(\mathrm{~d})$ & $54.94 \pm 5.46(\mathrm{c})$ & $68.42 \pm 2.00(\mathrm{~d})$ \\
\hline
\end{tabular}

The values presented are means of three replicates and standard deviations. Means were compared using the multiple range test of Duncan $(\alpha=0.05)$; differences were not significant for groups with the same letter.

L: Logarithmic phase; ES: early stationary phase; LS: late stationary phase.

\subsection{Proximate cellular composition}

The cellular contents of both $\mathrm{N}$ and $\mathrm{C}$ increased with the age of the culture, especially between early and late stationary phase (Table 2 ). The increase was higher in $\mathrm{C}$, consequently the ratio $\mathrm{C} / \mathrm{N}$ increased throughout the culture, with maxima at the late stationary phase. The $\mathrm{C} / \mathrm{N}$ ratio ranged from 8.24-9.41 for cells in the logarithmic phase to 10.46-13.29 for cells in late stationary phase. Regarding the $\mathrm{N}$ source, in the logarithmic phase, the $\mathrm{C} / \mathrm{N}$ ratio is significantly lower in urea cultures; no significant differences appear in $\mathrm{C} / \mathrm{N}$ ratio among the three $\mathrm{N}$ sources at early stationary phase, but at late stationary phase, this ratio is significantly lower in nitrite cultures (Table 2).

Table 2.

Cellular quotas $(\mathrm{Q})$ of $\mathrm{C}$ and $\mathrm{N}$ of I. galbana grown in different $\mathrm{N}$ sources and in different phases of the growth cycle

\begin{tabular}{llllll} 
Parameter & Phase & Nitrate & Nitrite & Urea \\
\hline QN (pg cell & L $)$ & L & $2.38 \pm 0.02(a, b, c)$ & $2.59 \pm 0.04(\mathrm{c})$ & $2.36 \pm 0.01(\mathrm{a}, \mathrm{b}, \mathrm{c})$ \\
& ES & $2.46 \pm 0.10(\mathrm{~b}, \mathrm{c})$ & $2.24 \pm 0.02(\mathrm{a}, \mathrm{b})$ & $2.20 \pm 0.07(\mathrm{a})$ \\
& LS & $3.10 \pm 0.11(\mathrm{~d})$ & $3.17 \pm 0.09(\mathrm{~d}, \mathrm{e})$ & $3.38 \pm 0.10(\mathrm{e})$ \\
\hline $\mathrm{QC}\left(\mathrm{pg} \mathrm{cell}^{-1}\right)$ & L & $19.20 \pm 0.09(\mathrm{a}, \mathrm{b})$ & $20.75 \pm 0.06(\mathrm{~b}, \mathrm{c})$ & $16.71 \pm 0.08(\mathrm{a})$ \\
& ES & $22.39 \pm 0.07(\mathrm{c})$ & $19.64 \pm 0.05(\mathrm{~b})$ & $19.40 \pm 0.11(\mathrm{a}, \mathrm{b})$ \\
& LS & $32.70 \pm 0.09(\mathrm{e})$ & $28.37 \pm 0.11(\mathrm{~d})$ & $38.43 \pm 0.15(\mathrm{f})$ \\
$\mathrm{C} / \mathrm{N}(\mathrm{mol} / \mathrm{mol})$ & L & $9.41 \pm 0.13(\mathrm{~b})$ & $9.35 \pm 0.15(\mathrm{~b})$ & $8.24 \pm 0.05(\mathrm{a})$ \\
& ES & $10.60 \pm 0.16(\mathrm{c})$ & $10.23 \pm 0.06(\mathrm{c})$ & $10.27 \pm 0.36(\mathrm{c})$ \\
& LS & $12.33 \pm 0.75(\mathrm{~d})$ & $10.46 \pm 0.38(\mathrm{c})$ & $13.29 \pm 0.38(\mathrm{e})$
\end{tabular}

The values presented are means of three replicates and standard deviations. Means were compared using the multiple range test of Duncan $(\alpha=0.05)$; differences were not significant for groups with the same letter.

L: Logarithmic phase; ES: early stationary phase; LS: late stationary phase.

The biochemical profile was more affected by the growth phase than by the nitrogen source. In the logarithmic phase, protein was the main constituent in all cultures, accounting for $37-45 \%$ 
AFDW (Table 3). Lipids were second, accounting for $22-32 \%$. Carbohydrates showed less variation during the exponential growth with values between $7.65 \%$ and $9.84 \%$ (Table 3 ). This pattern changed as the cultures aged and in the late stationary phase, lipids were the main constituents in cells grown in all nitrogen sources. Urea cultures showed significantly higher values of lipids than nitrate and nitrite cultures in the logarithmic and early stationary phases. The values of chlorophyll $a$ and carotenes as percentages of AFDW, decreased when populations entered the stationary phase, the decrease in chlorophyll a content being greater; therefore, the carotenoids/chlorophyll a ratio increased.

Table 3.

Biochemical composition, as \%AFDW, of I. galbana cells cultured with different $\mathrm{N}$ sources and in different phases of the growth cycle

\begin{tabular}{|c|c|c|c|c|}
\hline Parameter & Phase & Nitrate & Nitrite & Urea \\
\hline \multirow[t]{3}{*}{ Protein } & $\mathrm{L}$ & $40.19 \pm 0.79$ (b) & $37.36 \pm 1.23(b)$ & $44.96 \pm 0.83(\mathrm{c})$ \\
\hline & ES & $34.50 \pm 0.94$ (b) & $34.58 \pm 0.96(b)$ & $35.98 \pm 1.49$ (b) \\
\hline & LS & $28.01 \pm 1.31$ (a) & $33.46 \pm 1.41(\mathrm{~b})$ & $28.48 \pm 1.51(\mathrm{a})$ \\
\hline \multirow[t]{3}{*}{ Lipids } & $\mathrm{L}$ & $21.87 \pm 0.47$ (a) & $27.50 \pm 3.11$ (a) & $32.33 \pm 0.58(b)$ \\
\hline & ES & $34.03 \pm 0.58(b)$ & $33.58 \pm 0.58(b)$ & $42.05 \pm 0.51(\mathrm{c})$ \\
\hline & LS & $38.49 \pm 0.51(\mathrm{c})$ & $41.61 \pm 0.51(\mathrm{c})$ & $31.36 \pm 0.98(b)$ \\
\hline \multirow[t]{3}{*}{ Carbohydrates } & $\mathrm{L}$ & $7.65 \pm 0.43$ (a) & $8.19 \pm 0.50$ (a) & $9.84 \pm 0.44$ (b) \\
\hline & ES & $10.64 \pm 0.48(\mathrm{c})$ & $9.04 \pm 0.45$ (b) & $10.18 \pm 0.49(b, c)$ \\
\hline & LS & $11.95 \pm 0.47(\mathrm{~d})$ & $13.58 \pm 0.50(\mathrm{~d})$ & $10.85 \pm 0.47(\mathrm{c})$ \\
\hline \multirow[t]{3}{*}{ Chlorophyll $a$} & $\mathrm{~L}$ & $0.58 \pm 0.01(b)$ & $0.53 \pm 0.01(\mathrm{~b})$ & $0.78 \pm 0.02(\mathrm{c})$ \\
\hline & ES & $0.35 \pm 0.02$ (a) & $0.36 \pm 0.04$ (a) & $0.38 \pm 0.00$ (a) \\
\hline & LS & $0.26 \pm 0.05$ (a) & $0.28 \pm 0.08$ (a) & $0.31 \pm 0.02$ (a) \\
\hline \multirow[t]{3}{*}{ Chlorophyll $c$} & $\mathrm{~L}$ & $0.05 \pm 0.00(a, b)$ & $0.03 \pm 0.00$ (a) & $0.11 \pm 0.01(\mathrm{c})$ \\
\hline & ES & $0.08 \pm 0.01(\mathrm{c})$ & $0.10 \pm 0.02(\mathrm{c})$ & $0.13 \pm 0.01(\mathrm{~d})$ \\
\hline & LS & $0.05 \pm 0.01(a, b)$ & $0.06 \pm 0.01(b)$ & $0.08 \pm 0.00(\mathrm{c})$ \\
\hline \multirow[t]{3}{*}{ Carotenes } & $\mathrm{L}$ & $0.44 \pm 0.02(b)$ & $0.40 \pm 0.01$ (b) & $0.59 \pm 0.02(\mathrm{c})$ \\
\hline & ES & $0.31 \pm 0.01$ (a) & $0.35 \pm 0.02$ (a) & $0.34 \pm 0.01$ (a) \\
\hline & LS & $0.25 \pm 0.01$ (a) & $0.31 \pm 0.02$ (a) & $0.25 \pm 0.02$ (a) \\
\hline \multirow[t]{3}{*}{ Carotenoids/chlorophyll $a$} & $\mathrm{~L}$ & $0.75 \pm 0.04$ (a) & $0.76 \pm 0.01$ (a) & $0.77 \pm 0.01$ (a) \\
\hline & ES & $0.92 \pm 0.02$ (b) & $0.92 \pm 0.03$ (b) & $0.91 \pm 0.02(b)$ \\
\hline & LS & $0.94 \pm 0.15$ (b) & $1.06 \pm 0.10(\mathrm{c})$ & $1.33 \pm 0.11(\mathrm{c})$ \\
\hline
\end{tabular}

The values presented are means of three replicates and standard deviations. Means were compared using the multiple range test of Duncan $(\alpha=0.05)$; differences were not significant for groups with the same letter.

L: Logarithmic phase; ES: early stationary phase; LS: late stationary phase.

\subsection{Lipid composition}

Lipid composition of I. galbana grown with different nitrogen sources in the different growth phases is shown in Fig. 2. Little differences occurred in lipid fractionation, expressed as percentage of total lipid, among the different nitrogen sources. Lipid composition was more affected by the growth phase. In all cultures, neutral lipid increased with the growth phase, from 
$27-30 \%$ of total lipid in logarithmic phase to $54-61 \%$ in late stationary phase, whereas phospholipid decreased from $31-39 \%$ in logarithmic phase to $10-12 \%$ of total lipid in late stationary phase. The percentage of galactolipid was not affected by the growth phase, with values between $34 \%$ and $28 \%$ in nitrate cultures, $37 \%$ and $28 \%$ in nitrite cultures, and $40 \%$ and $35 \%$ in urea cultures.

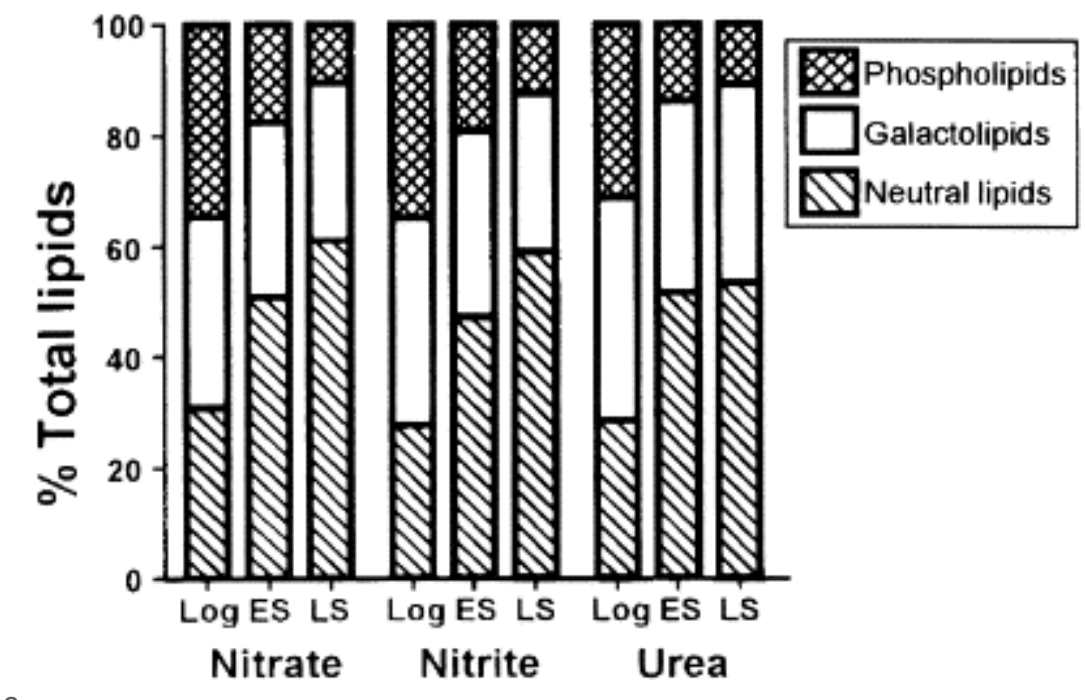

Fig. 2.

Relative proportions of the major lipid fractions in I. galbanacells cultured with different nitrogen sources and in different phases of the growth cycle.

\subsection{Fatty acid composition}

Total fatty acid cell content increased with culture time, from 103-125 mg g-1 DW of exponential cells to $146-177 \mathrm{mg} \mathrm{g}^{-1} \mathrm{DW}$ of late stationary cells, although maxima contents were obtained at early stationary phase in cells grown in nitrite and urea (Table 4). In this haptophyte, the main fatty acids, as percent of total fatty acids, were: 14:0 (9.8-19.9\%), 16:0 (12.2-18.8\%), 16:1n-7 (12.4-25.8\%), 18:4n-3 (7.1-15.4\%), 20:5n-3 (12.8-27.7\%) and 22:6n-3 (5.1-14.1). Reliable identification of $20: 0$ and $18: 3 n-4$ fatty acids was not possible under these analytical conditions due to their low occurrence.

Table 4.

Fatty acid composition (as \% of Total fatty acids) of I. galbana grown with different $\mathrm{N}$ sources and in different phases of the growth cycle

\begin{tabular}{|c|c|c|c|c|c|c|c|c|c|}
\hline \multirow[t]{2}{*}{ FA } & \multicolumn{3}{|c|}{ Nitrite } & \multicolumn{3}{|l|}{ Nitrite } & \multicolumn{3}{|l|}{ Urea } \\
\hline & $\mathrm{L}$ & $\mathrm{ES}$ & LS & $\mathrm{L}$ & ES & LS & $\mathrm{L}$ & ES & LS \\
\hline 14:0 & 19.23 & 14.44 & 10.27 & 18.51 & 12.70 & 12.50 & 19.93 & 10.25 & 9.80 \\
\hline $15: 0$ & 0.26 & 0.27 & 0.32 & 0.21 & 0.22 & 0.33 & 0.29 & 0.24 & 0.34 \\
\hline $16: 0$ & 14.94 & 12.58 & 18.62 & 13.86 & 12.58 & 18.81 & 17.74 & 12.17 & 18.00 \\
\hline $16: 1 n-7$ & 20.50 & 19.43 & 24.59 & 20.55 & 19.09 & 25.84 & 19.92 & 12.43 & 21.58 \\
\hline $16: 2 n-7$ & 0.41 & 0.33 & 0.22 & 0.40 & 0.34 & 0.20 & 0.32 & 0.41 & 0.28 \\
\hline $16: 2 n-4$ & 0.41 & 0.16 & 0.14 & 0.42 & 0.17 & 0.14 & 0.45 & 0.11 & 0.09 \\
\hline $16: 3 n-6$ & $\operatorname{tr}^{\mathrm{a}}$ & 0.16 & 0.10 & - & - & 0.40 & $\operatorname{tr}^{\mathrm{a}}$ & 0.11 & 0.14 \\
\hline
\end{tabular}




\begin{tabular}{|c|c|c|c|c|c|c|c|c|c|}
\hline \multirow[t]{2}{*}{ FA } & \multicolumn{3}{|l|}{ Nitrite } & \multicolumn{3}{|l|}{ Nitrite } & \multicolumn{3}{|l|}{ Urea } \\
\hline & $\mathrm{L}$ & ES & LS & $\mathrm{L}$ & ES & LS & $\mathrm{L}$ & ES & LS \\
\hline $18: 0$ & 0.52 & 0.42 & 0.67 & 0.79 & 0.20 & 0.54 & $\operatorname{tr}$ & 0.15 & 0.52 \\
\hline $16: 3 n-4$ & $\operatorname{tr}$ & $\operatorname{tr}$ & $\operatorname{tr}$ & $\operatorname{tr}$ & 0.13 & $\operatorname{tr}$ & $\operatorname{tr}$ & 0.07 & $\operatorname{tr}$ \\
\hline $18: 1 n-9$ & 1.78 & 1.41 & 2.37 & 1.48 & 1.29 & 2.02 & 1.53 & 1.17 & 2.07 \\
\hline $18: 1 n^{-7}$ & 1.76 & 1.68 & 3.88 & 1.99 & 2.11 & 4.08 & 1.79 & 1.17 & 2.66 \\
\hline $18: 2 n-6$ & 2.00 & 0.68 & 1.23 & 1.95 & 0.91 & 1.10 & 2.01 & 0.43 & 0.96 \\
\hline $18: 3 n-6$ & 0.54 & 0.33 & 0.41 & 0.96 & 0.26 & 1.18 & 0.61 & 0.20 & 0.35 \\
\hline $20: 0+18: 3 n-4$ & 0.29 & $\operatorname{tr}$ & 0.22 & - & - & 0.73 & 0.37 & - & - \\
\hline $18: 3 n-3$ & 1.37 & 1.23 & 0.68 & 1.04 & 1.03 & 0.73 & 1.19 & 1.88 & 0.67 \\
\hline $20: 1 n-9$ & $\operatorname{tr}$ & $\operatorname{tr}$ & 0.25 & 1.24 & 0.13 & 0.27 & $\operatorname{tr}$ & $\operatorname{tr}$ & 0.15 \\
\hline $18: 4 n-3$ & 12.03 & 14.28 & 8.30 & 11.71 & 13.99 & 7.06 & 12.13 & 15.37 & 9.78 \\
\hline $18: 4 n-1$ & 0.51 & 0.89 & 0.38 & 0.43 & 0.16 & 0.38 & $\operatorname{tr}$ & - & $\operatorname{tr}$ \\
\hline $20: 2 n-6$ & 0.41 & $\operatorname{tr}$ & 0.39 & $\operatorname{tr}$ & 0.14 & 0.35 & $\operatorname{tr}$ & 0.34 & 0.15 \\
\hline $20: 3 n-6$ & $b_{-}$ & - & 0.34 & - & - & 0.19 & $b_{-}$ & - & 0.45 \\
\hline $20: 4 n-6$ & $\operatorname{tr}$ & $\operatorname{tr}$ & 0.31 & 1.04 & 0.28 & 0.33 & $\operatorname{tr}$ & 0.34 & 0.43 \\
\hline $20: 4 n-3$ & $\operatorname{tr}$ & $\operatorname{tr}$ & - & $\operatorname{tr}$ & $\operatorname{tr}$ & $\operatorname{tr}$ & $\operatorname{tr}$ & $\operatorname{tr}$ & $\operatorname{tr}$ \\
\hline $20: 5 n-3$ & 14.64 & 19.09 & 16.14 & 14.94 & 22.74 & 13.10 & 12.76 & 27.66 & 19.69 \\
\hline $21: 5 n-3$ & 2.23 & 1.49 & 0.51 & 0.65 & 0.98 & 1.15 & 1.65 & 0.95 & 0.64 \\
\hline $22: 5 n-3$ & - & 1.64 & 0.48 & - & - & 0.51 & - & - & 0.56 \\
\hline $22: 6 n-3$ & 5.64 & 7.85 & 8.26 & 6.30 & 10.14 & 5.85 & 5.14 & 14.13 & 9.94 \\
\hline Total (mg g $\left.{ }^{-1} \mathrm{DW}\right)$ & 119.42 & 146.92 & 177.45 & 125.16 & 182.65 & 146.24 & 102.55 & 200.82 & 151.30 \\
\hline$\%($ SFA+MUFA) & 59.30 & 51.33 & 61.54 & 59.54 & 48.52 & 65.86 & 62.54 & 37.73 & 55.54 \\
\hline$\%$ PUFA & 40.70 & 48.67 & 38.46 & 40.46 & 51.48 & 34.14 & 37.46 & 62.27 & 44.46 \\
\hline$(\mathrm{SFA}+\mathrm{MUFA}) / \mathrm{PUFA}$ & 1.46 & 1.05 & 1.60 & 1.47 & 0.94 & 1.93 & 1.67 & 0.61 & 1.25 \\
\hline$n-6 / n-3$ & 0.09 & 0.03 & 0.09 & 0.13 & 0.04 & 0.13 & 0.09 & 0.03 & 0.07 \\
\hline
\end{tabular}

In the three media assayed, maxima PUFA values were obtained at the early stationary phase and decreased throughout this phase. Conversely, SFA and MUFA subtotals decreased the beginning of the stationary phase, presenting minima values at early stationary phase (Table 4). Isochrysis cells grown in nitrate or nitrite media showed very similar fatty acid patterns in any phase of growth, but slightly different from urea grown cells. Isochrysis cultured in urea media had the highest contents of saturated and monounsaturated fatty acids (SFAs+MUFAs) in the log phase. At the beginning of the stationary phase, these cells showed a sharp decline in these fatty acids and a strong increase in polyunsaturated fatty acids (PUFAs) ( Table 4). Therefore, PUFAs reached $62.27 \%$ of total fatty acids in the early stationary phase of cells grown in urea, as opposed to $48.63 \%$ and $51.48 \%$, obtained in nitrate and nitrite media, respectively, in the same phase ( Table 4). The highest content of eicosapentaenoic acid (EPA) (20:5n-3) and docosahexaenoic acid (DHA) $(22: 6 n-3)$ was obtained in urea cultures at the early stationary phase: EPA, $55.55 \mathrm{mg} \mathrm{g}^{-1} \mathrm{DW}\left(27.66 \%\right.$ of total fatty acids) and DHA, $28.37 \mathrm{mg} \mathrm{g}^{-1} \mathrm{DW}(14.13 \%$ 
of total fatty acids). Ratio of SFAs+MUFAs to PUFAs and that of $n-6$ PUFAs and $n-3$ PUFAs ( $n$ $-3 / n-6)$ declined at the beginning of the stationary phase and increased in later stages ( Table 4).

\section{Discussion}

Nitrate, nitrite and urea were suitable $\mathrm{N}$ sources for growth of I. galbana, but the nitrogen source affected the biochemical composition of cells. Changes in cellular composition have also been reported for Dunaliella tertiolecta (Fábregas et al., 1989) and P. tricornutum ( Fidalgo et al., 1995) cultured with different $N$ sources. Biochemical composition was also affected by the growth phase, as has been reported previously, particularly with respect to their lipid components (Sukenik and Carmeli, 1990; Hodgson et al., 1991). Not only the gross composition, but also lipid classes and fatty acids were affected.

The increase in cellular contents of $N$ and $C$ throughout the growth phase (Table 2) can be explained in function of the increase in cellular dry weight (Table 1), but lower variations occur if $\mathrm{N}$ and $\mathrm{C}$ are considered as \%DW, with values between $4 \%$ and $5 \%$ DW for $\mathrm{N}$ and $40-45 \%$ for $\mathrm{C}$. The increase in the ratio $\mathrm{C} / \mathrm{N}$ throughout the growth time is in accordance with the consumption of the available nitrogen of the culture media in a batch growth (Brown et al., 1993; Uriarte et al., 1993). Variations in $\mathrm{N}$ and $\mathrm{C}$ quotas and in $\mathrm{C} / \mathrm{N}$ ratio due to $\mathrm{N}$ source have also been reported in other marine microalgae (Levasseur et al., 1993).

The increase in the $\mathrm{C} / \mathrm{N}$ ratio indicates that the consumption of nitrogenous compounds can be the main cause of the relative decrease in the synthesis of protein and the increase in the synthesis of storage products observed throughout the growth cycle (Table 3 ).

Low protein and high carbohydrate contents were found in nitrate, nitrite and urea cultures at the stationary phase in $P$. tricornutum (Fidalgo et al., 1995). However, in I. galbanalipid appears as the main reserve product in all the nitrogen sources assayed. It has also been suggested that carotene/chlorophyll a ratio is inversely related to $\mathrm{N}$ status ( Davidson et al., 1991); in I. galbana carotenoids/chlorophyll a ratio increased throughout the culture in the three nitrogen sources assayed ( Table 3).

Lipids are important sources of energy for growing bivalve larvae (Webb and Chu, 1983; Gallager et al., 1986; Whyte et al., 1987). The relative amounts of each lipid class in microalgal cells can change considerably with variations in culture conditions (Yongmanitchai and Ward, 1989; reviewed by Roessler, 1990). Triacylglycerols (neutral lipids) are considered to be storage lipids for algae (Sukenik and Carmeli, 1990); the more polar lipid fractions are likely to be associated with the photosynthetic membranes of the algae. Triacylglycerols increased between exponential and stationary phases (Fig. 2).

The proportions of the two polar lipid fractions of the total lipids were generally highest in the logarithmic phase. In the early stationary phase, the proportion of galactolipids slightly declined, whereas there was a strong decrease in the phospholipids fraction (from $31-34 \%$ of total lipids to $10-12 \%)$ for all the nitrogen sources assayed. Similar results were found in three species of 
marine microalgae (Dunstan et al., 1993): stationary phase cultures of all three species showed increased proportions (\%) of triacylglycerols with correspondingly decreased proportions of polar lipids relative to logarithmic phase cultures. However, no significant differences were found in lipid fractionation among the nitrogen sources assayed.

Generally, accumulation of triacylglycerols has been correlated with the cessation of cellular division at the onset of stationary phase in aged cultures (Hodgson et al., 1991). The phenomenon appears to be a complex matter of the dynamics of cellular division, nitrogen metabolism, and photosynthetic fixation of carbon (Suen et al., 1987; Sukenik and Carmeli, 1990).

Some of the variations in the fatty acid composition of I. galbana ( Table 4) caused by the growth phase can be related to the relative distribution of the major lipid classes in this alga. The C18:1 and C16:0 fatty acid percentage increased as the relative content of neutral lipids increased, mostly under severe nitrogen-limiting conditions as occurred in the late stationary phase. Similar results were found by Sukenik and Wahnon (1991).Urea media yielded higher contents of total fatty acids as mg per $\mathrm{g}$ of dry weight, at the beginning of the stationary phase. Amounts of PUFAs, as $\mathrm{mg} \mathrm{g}^{-1} \mathrm{DW}$ followed a similar pattern, representing the $62.5 \%$ of total fatty acids. Because the $n-3$ family of fatty acids are essential in the diets of many commercially important marine fish and shellfish (Sargent et al., 1989) it is in the interest of the aquaculturist to maximize the production of the $n-3$ family of fatty acids in dietary algae used in culture of larvae of many marine species ( Hodgson et al., 1991). Urea grown cells showed at the beginning of stationary phase the highest relative abundances of the $n-3$ PUFAs linolenic acid (18:3n-3), eicosapentaenoic acid and docosohexaenoic acid (about 2\%, 28\% and 14\%, respectively). Therefore, urea could be a good nitrogen source to culture I. galbana to maximize PUFA production, and harvesting the biomass at specific growth phases may enable better yields in lipid and PUFA composition. Lower ratios SFA+MUFAs to PUFAs and $n-6$ to $n-3$ PUFAs were also obtained in urea cultures, followed by nitrite cultures. These ratios are considered of nutritional value in bivalve nutrition. Diets with lower values of SFA+MUFAs to PUFAs and ratios $n-6: n-3<0.5$ were optimal for larvae and juvenile oysters (Webb and Chu, 1983; Enright et al., 1986). Urea is one of the lowest cost nitrogen source for microalgal culture. Similar results have been obtained in P. tricornutum ( Yongmanitchai and Ward, 1991; Fidalgo et al., 1995). These findings indicate that the opportunity exists to maximize PUFA production by microalgae with the potential to improve animal growth and reduce production costs in mariculture operations and may be of use in the large scale culture and harvesting of microalgae for the biotechnology industry ( Dunstan et al., 1993).

\section{Acknowledgements}

This work was supported by a grant from CICYT (I+D), Madrid, Spain (no. AGF920736).

\section{References}


A.O.A.C., 1980. Official Methods of Analysis, 13th edn. Association of Official Agricultural Chemists. Washington, DC.

M.R. Brown, S.W. Jeffrey, C.D. Garland

Nutritional aspects of microalgae used in mariculture: a literature review

CSIRO Mar. Lab. Rep., 205 (1989), p. 44

M.R. Brown, C.D. Garland, I.D. Jeffrey, J.M. Leroi

The gross and amino acid composition of batch and semicontinuous cultures oflsochrysis sp. (clone T.ISO), Pavlova lutheri and Nannochloropsis oculata

J. Appl. Phycol., 5 (1993), pp. 285-296

K. Davidson, K.J. Flynn, A. Cunningham

Relationships between photopigments, cell carbon, cell nitrogen and growth rate for a marine nanoflagellate

J. Exp. Mar. Biol. Ecol., 153 (1991), pp. 87-96

De Pauw, N., Persoone, G., 1988. Microalgae for aquaculture. In: Borowitzka, M.A., Borowitzka, L.J. (Eds.), Microalgal Biotechnology. Cambridge Univ. Press, Cambridge, pp. 197-221

\section{G.A. Dunstan, J.K. Volkman, S.W. Jeffrey, S.M. Barrett}

Biochemical composition of microalgae from the green algal classes Chlorophyceae and Prasinophyceae:

2. Lipid classes and fatty acids

J. Exp. Mar. Biol. Ecol., 161 (1992), pp. 115-134

\section{G.A. Dunstan, J.K. Volkman, S.M. Barrett, C.D. Garland}

Changes in the lipid composition and maximisation of the polyunsaturated fatty acid content of three microalgae grown in mass culture

J. Appl. Phycol., 5 (1993), pp. 71-83

C.T. Enright, G.F. Newkirk, J.S. Craigie, J.D. Castell

Evaluation of phytoplankton as diets for juvenile Ostrea edulis L.

J. Exp. Mar. Biol. Ecol., 96 (1986), pp. 1-13

J. Fábregas, J. Abalde, B. Cabezas, C. Herrero

Changes in protein, carbohydrates and gross energy in the marine microalga Dunaliella tertiolecta (Butcher) by nitrogen concentrations as nitrate, nitrite and urea

Aquacult. Eng., 8 (1989), pp. 223-239

M.J. Fernandez-Reiriz, A. Perez-Camacho, M.J. Ferreiro, J. Blanco, M. Planas, M.J. Campos, U. Labarta Biomass production and variation in the biochemical profile (total protein, carbohydrates, RNA, lipids and fatty acids) of seven species of marine microalgae

Aquaculture, 83 (1989), pp. 17-37 
J.P. Fidalgo, A. Cid, J. Abalde, C. Herrero

Culture of the marine diatom Phaeodactylum tricornutum with different nitrogen sources: growth, nutrient conversion and biochemical composition

Cah. Biol. Mar., 36 (1995), pp. 165-173

\section{S.M. Gallager, R. Mann, G.C. Sasaki}

Lipid as an index of growth and viability in three species of bivalve larvae

Aquaculture, 56 (1986), pp. 81-103

E. Gnaiger, G. Bitterlich

Proximate biochemical composition and caloric content calculated from elemental $\mathrm{CHN}$ analysis: a stoichiometric concept

Oecologia, 62 (1984), pp. 289-298

P.A. Hodgson, R.J. Henderson, J.R. Sargent, J.W. Leftley

Patterns of variation in the lipid class and fatty acid composition of Nannochloropsis oculata (Eustigmatophyceae) during batch culture: I. The growth cycle

J. Appl. Phycol., 3 (1991), pp. 169-181

Kaplan, D., Richmond, A.E., Dubinsky, Z., Aaronson, S., 1986. Algal nutrition. In: Richmond, A. (Ed.), Handbook of Microalgal Mass Culture. CRC Press, FL, pp. 147-198.

Kochert, G., 1978. Carbohydrate determination by the phenol-sulfuric acid method. In: Hellebust, J.A., Craigie, J.S. (Eds.), Handbook of Phycological Methods. Physiological and Biochemical Methods. Cambridge Univ. Press, Cambridge, pp. 95-97.

W.M. Koven, G.Wm. Kissil, A. Tandler

Lipid and $n-3$ requirement of Sparus aurata larvae during starvation and feeding

Aquaculture, 79 (1989), pp. 185-191

M. Levasseur, P.A. Thompson, P.J. Harrison

Physiological acclimation of marine phytoplankton to different nitrogen sources

J. Phycol., 29 (1993), pp. 587-595

J.B. Marsh, D.B. Weinstein

Simple charring method for determination of lipids

J. Lipid Res., 7 (1966), pp. 574-576

Miller, L., 1984. Gas-liquid chromatography of cellular fatty acids as a bacterial identification aid. HewlettPackard, Gas Chromatography Application No. 228-237.

P.G. Roessler

Environmental control of glycerolipid metabolism in microalgae: commercial implications and future research directions 
J. Phycol., 26 (1990), pp. 393-399

Sargent, J.R., Henderson, R.J., Tocher, D.R., 1989. The lipids. In: Halver, J.E. (Ed.), Fish Nutrition. Academic Press, pp. 153-218.

Y. Suen, J.S. Hubbard, G. Holzer, T.G. Tornabene

Total lipid production of the green alga Nannochloropsis sp. QII under different nitrogen

J. Phycol., 23 (1987), pp. 289-296

\section{A. Sukenik, Y. Carmeli}

Lipid synthesis and fatty acid composition in Nannochloropsis sp. (Eustigmatophyceae) growth in a lightdark cycle

J. Phycol., 26 (1990), pp. 463-469

A. Sukenik, R. Wahnon

Biochemical quality of marine unicellular algae with special emphasis on lipid composition: I. Isochrysis galbana

Aquaculture, 97 (1991), pp. 61-72

\section{A. Sukenik, Y. Carmeli, T. Berner}

Regulation of fatty acid composition by irradiance level in the esustigmatophyteNannochloropsis sp.

J. Phycol., 25 (1989), pp. 686-692

A. Sukenik, O. Zmora, Y. Carmeli

Biochemical quality of marine unicellular algae with special emphasis on lipid composition: II. Nannochloropsis sp.

Aquaculture, 117 (1993), pp. 313-326

\section{Y. Uriarte, A. Faŕias, A.J.S. Hawkins, B.L. Bayne}

Cell characteristics and biochemical composition of Dunaliella primolecta Butcher conditioned at different concentrations of dissolved nitrogen

J. Appl. Phycol., 5 (1993), pp. 447-453

Vonshak, A., 1986. Laboratory techniques for the cultivation of microalgae. In: Richmond, A. (Ed.), Handbook of Microalgal Mass Culture. CRC Press, FL, pp. 117-145.

Webb, K.L., Chu, F.-L.E., 1983. Phytoplankton as a source for bivalve larvae. In: Pruder, G.D., Langdon, C., Conklin, D. (Eds.), Proceedings of 2nd International Conference on Aquaculture Nutrition: Biochemical and Physiological Approach to Shellfish Nutrition. Louisiana State Univ. Baton Rouge, LA, pp. 272-291.

J.N.C. Whyte, N. Bourne, C.A. Hodgson

Assessment of biochemical composition and energy reserves in larvae of the scallopPatinopecten yessoensis

J. Exp. Mar. Biol. Ecol., 113 (1987), pp. 113-124 
Yongmanitchai, W., Ward, O.P., 1989. $\omega-3$ fatty acids: alternative sources of production. Process Biochem., August, 117-125.

W. Yongmanitchai, O.P. Ward

Growth of and $\omega-3$ fatty acid production by Phaeodactylum tricornutum under different culture conditions Appl. Environ. Microbiol., 57 (1991), pp. 419-425

Corresponding author. Tel.: +34-81-167000; Fax: +34-81-167065; E-mail: herreroc@udc.es Copyright @ 1998 Elsevier Science B.V. All rights reserved. 